\title{
SLOW FOOD AND TOURISM DEVELOPMENT: A CASE STUDY OF SLOW FOOD TOURISM IN UTTARAKHAND, INDIA
}

\author{
Munish AHLAWAT* \\ Amity School of Hospitality, Amity University Uttar \\ Pradesh, Noida, India, e-mail: ahlawat22@gmail.com \\ Piyush SHARMA \\ Amity Institute of Travel and Tourism, Amity University \\ Uttar Pradesh, Noida, India, e-mail: psharma3@amity.edu

\section{Prashant Kumar GAUTAM} \\ University Institute of Hotel and Tourism Management, Panjab \\ University, Chandigarh, India, e-mail: prashant.k.gautam@gmail.com
}

\begin{abstract}
Citation: Ahlawat, M., Sharma, P., \& Gautam, P.K. (2019). SLOW FOOD AND TOURISM DEVELOPMENT: A CASE STUDY OF SLOW FOOD TOURISM IN UTTARAKHAND, INDIA. GeoJournal of Tourism and Geosites, 26(3), 751-76o. https://doi.org/10.30892/gtg.26306-394
\end{abstract}

\begin{abstract}
Abstract: Slow food has emerged as an unexplored contributor to promotion of local tourism. The objective of the present study is three-fold; to identify the various slow food being served in Uttarakhand, to recognize scope of development of slow food tourism by perception of major stakeholders, and to discuss recent developments that have enabled its growth in the state. The study employs unstructured, multi-stakeholder interview method across 5 tourist destinations among 680 respondents- including tourists, travel agents and guides, hotel and restaurant managers, and local population. The results of the study find a rich diversity of slow food cuisine, and identify five key factors in the development of slow food tourism in Uttarakhand, namely; Government support and financial aid, improved infrastructure, inter-industry cooperation, local and public awareness, and marketing. Several recent government policies and initiatives have been discussed in light of their positive impact on developing slow food tourism.
\end{abstract}

Key words: Slow food, slow food tourism, slow food development, local food, gastronomy tourism, Uttarakhand, India

\section{INTRODUCTION}

Over the past few years, tourism has experienced continued growth and deepening diversification to become one of the fastest growing economicsectors in the

\footnotetext{
* Corresponding author
} 
world. It has become a major player in the world trade, since according to the Travel and Tourism Global Economic Impact (2018) report travel and tourism directly contributed USD 8.3 trillion to global economy and supported 313 million jobs. According to the United Nations World Tourism Organization (2018), international tourism receipts have grown above USD 1.33 trillion in the year 2018, at a 3 percent growth rate from the previous year. The top three countries in the world on the basis of international tourism receipts in 2018 are namely; USA (USD 210.7 billion), Spain (USD 68 billion) and France (USD 60.7 billion). India stands seventh among 184 countries in terms of contribution of travel and tourism sector to GDP. Tourism in India is important for the country's economy and it is growing rapidly. Over 10 million foreign tourists arrived in India in 2017, compared to 8.89 million in 2016, representing a growth of $15.6 \%$. In January-October 2018, tourist arrivals through e-visa in India increased at 44.8 per cent year-on-year to 1.80 million. This sector is predicted to grow at an annual rate of $6.9 \%$ to 32.05 lakh crore (US $\$ 450$ billion) by 2028 (9.9\% of GDP).

India's foreign exchange earnings (FEEs) from tourism sectorincreased by 8.3 percent to US\$23.54 billion in January-October 2018.India enjoys great advantages in tourism scenario- unparalleled natural beauty, rich history and a treasure trove of cultural diversity. Modern tourists are looking to expand their worldview beyond sightseeing by indulging in travel experiences that cater to their individual interests and delights. The popular acceptance of culture- oriented travel experience has opened rich avenues for specific branches of tourism. Culinary tourism is a part of immersion tourism. Immersion tourism refers to the travel to a particular place with a purpose of experiencing its history, culture, people and cuisines. The Global Report on Food Tourism, published by United Nations World Tourism Organization, suggests that one third of the holiday budget of an average tourist is spent on food.

It is therefore indisputable that food forms a key portion of the travel experience at any tourist destination. Popularizing slow food, or local and regional culinary habits, can generate deeper interest and excitement in visiting a particular tourist spot, which can act as a catalyst for local tourism. Slow food tourism is inspired from the Slow Food Movement, which began as an effort to promote regional ways to establish cultural identity by recognizing the important role of food habits in a community and heritage (Kivela \& Crotts, 2005). Slow food tourism focuses on culinary consumption to be a wholesome travel experience in itself that involves rest, escapism, learning, thrill, status and lifestyle (Santich, 2004). Slow food tourism also benefits from other attributes like originality, variety and authenticity (Tellstrom et al., 2006). These factors play a huge role in building the attractiveness of a potential tourist destination.

Tourism based on culinary temptations and delights has been experimented to great results in several countries around the world. Special events like food festivals and fairs are conducted to harness nostalgia and cultural diversity and reap the vast economic profits of slow food tourism (Upadhyay \& Sharma, 2014). Further, the environmental and social benefits of valuing locally-grown and traditionally cooked meals over mass-produced fast food are added incentives for promoting slow food tourism. The influx of tourists and economic prosperity leads to better infrastructure and investments, which begins a cycle of growth and development. Thus, slow food can play a very significant role in promotion of a tourist destination.

There is a growing interest in identifying the scope of slow food in developing a tourist destination to realize its complete potential. There is a need of relevant research into the importance of slow food tourism in the context of locations with developing tourism industries like India. Each of the 29 states of India has its own distinct iden tity, terrain, communities, languages and dialects and an amazing and unique food history 
and heritage. The present study offers an insight into the potential of slow food tourism development in the small state of Uttarakhand, India. Uttarakhand, located in North India, has a population of above 1 crore (Census, 2011), a predominantly hilly terrain. Uttarakhand is divided into major divisions, namely, Garhwal and Kumaon. The state is also known by the name- Devbhumi, meaning, 'Land of the Gods', which is a nod to the myriad holy sites scattered in its territory. Its tourism industry is currently based on exploration of scenic landscapes, environmental preserves and religious pilgrimages. The state saw a tourist inflow of above 34.7 million tourists in a year (2017), with popular destinations being the cities of Haridwar, Dehradun, Mussoorie and Rudraprayag. This implies that Uttarakhand has the requisite infrastructure and support for a flourishing tourism market, and can develop further by adopting slow food tourism in its folds. This scenario makes Uttarakhand an interesting area of research for the development of slow food tourism. The state of Uttarakhand is a food enthusiast's dream come true with its incredible collection of delectable food items. Being located on the hills, the ingredients involved in making traditional food are free of any sort of adulteration, ensuring high nutrition and health benefits.

For achieving the objectives of this study, researchers have firstly provided a review of relevant literature on slow food movement, slow food tourism and its importance. Researchers have then gathered primary data from various stakeholders across five popular tourist destinations of the state regarding the scope of slow food tourism in Uttarakhand. Based on content analysis of the responses collected, researchers have discussed the factors that have contributed to the role of slow food in tourism industry. Finally, researchers have supported their findings with secondary data and discussed ground developments that have occurred in the political and social scenario, in terms of realization of slow food tourism.

The study concludes with an overall summary of key points in this paper, and also presents recommendations for tourism industry and the government. Lastly, the practical implications and limitations of this study have been discussed.

\section{REVIEW OF LITERATURE}

The present paper is an examination of scope of slow food and development of slow food tourism in Uttarakhand. The following review of literature examines relevant studies about food, its role in tourism industry, the creation of food-specific tourism, the overall relevance of such tourism, and finally, the factors that have contributed to its development. Food is an integral element to a tourist destination and can have substantial role to play in building the popularity of a destination (Banerjee et al., 2015). The cause behind such impact of food in a travel experience is the association of food with memory and emotions of nostalgia. Hashimoto and Telfer (2006) have highlighted that the concept of 'culinary tourism' was developed in the late 1990s, which succeeded in labelling the specific brand of tourism which catered to tourists expressing local and regional food culture as an important dynamic in travel. Everett and Atchison's (2008) study pointed out the important role of food in experiencing the full picture of Cornish culture and heritage. Similarly, Baltescu (2016) revealed that culinary experiences heavily influenced tourists' perspectives towards different destinations in Romania.

The idea behind slow food tourism is to inspire tourists to indulge in the rich diversity of locally- grown food (Miele \& Murdoch, 2002). The larger motive of slow food tourismis the endeavor to promote social connection and environmental conservation and sustainability (Quan \& Wang, 2004). As per Sidali et al., (2015), slow food tourism brings sustainability practices and financial independence to local entrepreneurs and social community. It also maximizes the tourist satisfaction and influences tourist behavior 
(Karim et al., 2009). Studies identify various components as major factors of healthy slow food tourism- local restaurants or hotels, food events, food festivals and variety of foods (Rand et al., 2003). Atton (2003) argues that the social awareness factors that could lead to success of slow food development are traditional culture, biodiversity and social justice. The method and style of serving food adds another layer of cultural diversity and uniqueness to the experience (Jiménez Beltrán et al., 2016), which makes the hospitality sector play an important role in its development. It is then imperative that tourist organizations therefore not fail to capitalize on slow food's scope and potential and demand to promote the development of slow food tourism.

\section{RESEARCH GAPS}

Despite being in good rankings globally and hosting a vast length and breadth of multiple cuisines within the country, India has not seen many studies on slow food tourism development in its states. While present literature on slow food shows a general understanding and assessment of slow food movements across the globe, there is a gap in state-specific studies on slow food tourism development in India. There has also been a considerable lack of studies that involve the perspectives of various stakeholders in the tourism sector namely; local people, tourist guides and agencies, hospitality sector service providers, and the tourists themselves. The present study will bridge these gaps in literature by identifying the scope of slow food tourism in Uttarakhand. Further, using data collected from various stakeholders, the key factors involved in development of slow food tourism in Uttarakhand shall be identified and discussed. Lastly, the study will also highlight the key developments that have taken place in the field.

\section{Objectives:}

1. To identify the various slow food being served in Uttarakhand.

2. To identify the scope of the slow food tourism in Uttarakhand. tourism.

3. To identify the recent developments in the Uttarakhand regarding slow food

\section{RESEARCH METHODOLOGY}

Current study is principally based on the primary data collected from various stakeholders in the state of Uttarakhand. Researchers have opted for unstructured, open-ended interview method since there was a lack of relevant and specific studies on slow food tourism development in Uttarakhand, and to understand the full scope of development of slow food tourism. Respondents selected for the survey were selected through snowball method of data collection; researchers have approached 56 employees and managers in 25 popular hotels across Uttarakhand for collecting primary data about the scope and factors of slow food in the state. These hotels were based in the top five districts of Uttarakhand, according to the number of tourist arrivals in 2018. Based on the responses and recommendations of these hoteliers and employees, researchers have further expanded the pool of respondents to include 70 restaurant managers, 32 tour guides and 37 travel agents. To fully understand the vast opportunities of development of slow food tourism in Uttarakhand, researchers have also included data collected from a random sample of 156 tourists visiting Uttarakhand as well as 329 local people. Thus, the total number of respondents in the study adds up to 680, providing subjective data from all stakeholders in the tourism industry of the state.

The interview method followed by the researchers included questions put to the respondents about the current state of tourism and slow food in Uttarakhand, as well as the further scope of its growth and expansion. Respondents were also asked to identify the key areas in slow food tourism that required increased attention. Researchers have 
also obtained information regarding the various factors that were perceived to play a significant role in the development of slow food tourism. Finally, the interview methodology also resulted in primary data about the perceived challenges and barriers to the emergence of slow food tourism as a vital part of the economy of Uttarakhand.

On the basis of primary data, collected from 680 respondents across the major destinations of Uttarakhand, researchers have conducted a content analysis to derive findings about the present scenario of slow food tourism. The assessment of primary data has shown that there was a large consensus over the role of five key factors in the growth of slow food tourism in Uttarakhand, which have been discussed in the next section.

Researchers have supported the primary data with additional secondary data. Statistics and information about recent developments in Uttarakhand by the state and central government for the development of tourism sector have been discussed in section 3 below. Relevant data has been collected from a variety of sources. The purpose of using secondary data as well was to present an objective and practical insight into the key trends in development of slow food tourism in Uttarakhand.

\section{FINDINGS AND DISCUSSIONS}

The results of content analysis of the collected primary data presented interesting findings for the present status of slow food tourism in the state of Uttarakhand, as presented below. The first section identifies the scope of slow food tourism in Uttarakhand, while the second section identifies and discussed the factors that contribute towards slow food tourism from the perspective of stakeholders in the sector.

Lastly, the third section utilizes secondary information gathered from government releases and news reports about the key developments made regarding tourism and slow food in Uttarakhand.

\section{Slow food being served in Uttarakhand}

The food offered in the pure environment amid hills and valleys of Uttarakhand is bursting with authentic flavors. Both Garhwali and Kumaoni cuisines stay authentic to food's natural tastes without an overpowering melee of spices. All food preparations are rich in nutrient factor and since they are imbibed with various herbs, lentils, cereals and pulses, they hold a staggering number of health benefits. Five tourist destinations, namely, Haridwar, Dehradun, Nainital, TehriGarhwal and Kedarnath, are major attractions for different kinds of tourism. Due to the existing presence of requisite tourism infrastructure such as hotel availability and well- equipped travel agencies; these sites are also primed for immediate development of slow food tourism in Uttarakhand. Findings from the research show that several hotels and restaurants at these tourist destinations serve slow food; the development of slow food tourism thus shows a vast scope of improvement in these places.

\section{Role of Stakeholders in Tourism Sector}

The ambit of slow food tourism at any place can be reasonably examined only after taking the viewpoint of all stakeholders into account. Hashimoto and Telfer (2006) stated that opinions and contributions of major stakeholders should be considered for a holistic view of the scenario prevailing in slow food tourism development. The input of these stakeholders in the development of slow food tourism is the backbone of this serviceoriented industry. It hence follows to present a short discussion on the role of these stakeholders in slow food tourism development in Uttarakhand.

Tourists are at both the giving and receiving end of the spectrum of tourism industry. In certain places, food tourism occupies a majority chunk of the tourists visiting the destination. Since food can transform tourists' attitude towards slow food and create memory and nostalgia (Quan \& Wang, 2004), the places that have few tourist 
destinations can use slow food to capitalize on cultural treasures (Santich, 2004). Another important stakeholder in tourism sector is the hospitality sector. Restaurants at popular destinations typically earn about 50 percent of their revenue from travelers' pockets (McKercher et al., 2008). Local population occupies a major stake in slow food tourism since it involves the cooperation and support by local people to exist. Local populace onlygives the cuisine of a country its cultural and regional identity (Rand et al., 2003). Therefore, researchers have taken care to include the insights and perspective of all affected stakeholders in the slow food tourism sector of Uttarakhand.

Among total 680 respondents, a large section comprised of tourists and local population, i.e. 156 and 329 respondents respectively. Apart from this, 56 hoteliers from 25 popular hotels and 70 restaurant managers are also included. Further data has been derived from the perspectives of 37 travel agents and 32 tourist guides, for a thorough understanding of the vast ambit of slow food tourism in Uttarakhand. Uttarakhand features great delicious diversity in its traditional cuisine. The following table (Table 1) lists slow food options identified in Uttarakhand, and the availability of the slow food between the two main districts of Uttarakhand, namely Garhwal and Kumaon.

Table 1. List of Slow Food Options and Availability in Uttarakhand

\begin{tabular}{|c|c|c|}
\hline Type of SSow Food & Garhwali District & Kumaoni District \\
\hline Beverage & - Burans Ras & - Thandai \\
\hline Food & $\begin{array}{l}\text { - Thenchwani } \\
\text { - GarhwalkaFannah } \\
\text { - Phaana } \\
\text { - Kaafuli } \\
\text { - Kodeki Roti } \\
\text { - Chaunsu }\end{array}$ & $\begin{array}{l}\text { - Bhatt Churkhani } \\
\text { - AlooGutke } \\
\text { - Bhang Chutney } \\
\text { - Dubuk } \\
\text { - Kumaoni Dal Vade } \\
\text { - KadaleekaSaag }\end{array}$ \\
\hline Desserts & $\begin{array}{l}\text { - Singori } \\
\text { - Jhangoraki Kheer }\end{array}$ & - Arsa \\
\hline Snacks & $\begin{array}{l}\text { - Baadi } \\
\text { - Gulgula }\end{array}$ & $\begin{array}{ll}\text { - } & \text { AlooTuk } \\
\text { - } & \text { Kumauni Raita }\end{array}$ \\
\hline
\end{tabular}

The above table indicates that there is a vast variety of slow food options in Uttarakhand, which makes it an exciting venue for slow food tourism. The authenticity of its cuisine is not marred by homogeneity of taste and culture; Uttarakhand indeed promises thrilling and exciting meals for tourists from any section of the world.

\section{Perspective) \\ Key Factors in Slow Food Tourism in Uttarakhand (Stakeholders'}

There is need for discussion into the key factors that can influence the growth of slow food tourism. The following section discusses the key factors of slow food tourism from the stakeholders' perspective considered in this study.

\section{Government Support and Financial Aid}

The greatest factor in growth of tourism sector in any country is the support for its development given by its government. Some key responsibilities of the ministry of tourism are augmenting tourism infrastructure, easing of visa regime, and assurance of quality standards etc. The stakeholders surveyed in the study pointed out in a general consensus that for the promotion of slow food tourism, the government should be required to provide financial support to new businesses in the market. Such financial support could take the shape of subsidies, tax exemptions and business loans at low interest rates. This aid is required to protect investments and direct capital inflow into the development of this sector. 


\section{Inter-Industry Cooperation}

This means forming healthy associations with rural food providers and raw material suppliers, and agencies for transport and communication. The cooperation and the understanding between the food industries and the tourism agencies is required. Further, the benefits to such business understandings are mutual; travel agencies and tour guides can help boost slow food by ensuring that the tourists interested in having a wholesome experience of travel are recommended hotels and restaurants that actively serve slow food. Similarly, hotels and restaurants pay back the favor by hiring tour guides to highlight the history and cultural value of a select dish.

\section{Improved Infrastructure}

The augmentation of tourism infrastructure includes basic amenities like transport and communication connectivity, public hygiene facilities, electricity and power, or ease of accommodation and service options. It is also essential to have a robust safety and security situation for tourists. Uttarakhand can utilize the foundations of existing infrastructural abilities for the initial development of slow food tourism. Apart from physical infrastructure, improvement in training and skill capital is also an important driver for growth in slow food tourism. Language barriers and lack of information can act as major barriers to enjoyment of slow food served to tourists (Amuquandoh, 2011). Employees of hotels and restaurants were found to be trained regularly in service skills, communication abilities and customer engagement methods.

\section{Local Public Support and Awareness}

Slow food is not merely the consumption of food; it includes the immersion of local culture into the enjoyment of food. The ambience around slow food makes it more attractive and tempting for tourists as a cultural experience on trips and holidays (Kim et al., 2009). In this experience, it is vital that they are supported by an aware local population about the nutritious benefits and enjoyment of slow food. Enthusiasts of slow food are keenly interested to know about the recipes and exotic ingredients that go into the making of slow food of that area.

\section{Marketing \& Promotion}

Highlighting beneficial attributes is a crucial factor in the advancement of slow food tourism. Travel guides and tour operators indicated positive response to organizing customized tours focused on spreading knowledge about local food and culture. The business agents also showed interest in promoting slow food through specially curated restaurants and local motels for tourists. A major marketing gimmick for promoting slow food tourism can be conducted in the form of food fairs and festivals (Jung et al., 2015). Such fairs are a magnetic attraction to food- loving tourists from anywhere in the world. The success of such fairs and festivals can bring great economic profits, especially in rural or lesser known areas.

\section{Recent Developments in favor of Slow Food Tourism}

It is essential to take a look into the developments made in Uttarakhand's tourism industry over the years. These developments have had direct and indirect roles to play in the promotion of slow food tourism as well. The state's overall tourism policy is based on developing Uttarakhand's tourist destinations with special focus on pilgrimage and adventure tourism. The following section details major developments that have been carried out in the state and how they have influenced the growth of slow food tourism.

\section{Infrastructure}

The government of Uttarakhand spends considerable resources in the augmentation of quality infrastructure in the tourism industry. The government has also provided financial infrastructure for supporting development of slow food tourism in Uttarakhand. In the revenue surplus budget of 2019-2020, several provisions have been 
made to boost the agricultural sector and lifestyle of farmers. Traditional crops like coarse grains, cereals etc. have been allotted additional budget of INR 104 crores for their promotion. Tourism is heavily reliant on availability of connectivity infrastructure- through roads, railway, airways and other modes of transportation. Uttarakhand government has made transportation and connectivity a top priority to ensure uninterrupted functioning of tourism industry. In terms of transport infrastructure, a breakthrough achievement was recently conducted in the shape of the largest ropeway project in the country between Mussoorie and Dehradun. The Dehradun-Mussoorie Ropeway project would provide a host of facilities for ease of tourism, including waiting lounges, food and retail counters and public amenities.

\section{Public Awareness}

For slow food tourism to sustainably exist, it must exceedingly tempt tourists from across the world about its variety, value and benefits. Public funds are to be provided for launching awareness programs, and for undertaking requisite preservation efforts. A major marketing campaign Incredible India 2.0 featured thematic creatives on niche tourism branches, including culinary or slow food tourism. Another key development in the direct promotion of slow food tourism in Uttarakhand has been through various food festivals held in the state. Several special food fairs and fests have been organized which have brought attention to Uttarakhand's traditional cuisine. Local and national media have also given attention to such organizations, which furthers their popularity. Uttarakhand government has also spread public awareness campaigns regarding the safety and security of tourists. The government releases several guidelines for the safety of tourists at regular intervals.

\section{Quality Control}

Health and hygiene are of crucial importance for many tourists and the government of Uttarakhand has taken measures to ensure complete cleanliness within the state. In 2018, the efforts of Uttarakhand state government were publicly lauded by central government and its policies were highly recommended to be followed by other states as well. The revival measures for river Ganga has had major impact on slow food tourism, since Ganga fulfilled the food grain demand of 45 percent of the local population and was the backbone of agriculture in the state. Government's development plans for the state also predict to clean all sewage lines by 2020. This focus on neatness and hygiene shall build the attractiveness of Uttarakhand as a tourist destination. In terms of slow food tourism, ambience of the local region is vital to the enjoyment of slow food. Uttarakhand government has strict licensing requirements under the Food Safety and Standards Authority of India for food business operators.

\section{Training}

Good service quality increases the chance of revisiting and remembrance by old tourists, and further welcomes new ones. Uttarakhand government has realized the scope of tourism industry in the economy. The training at several hos pitality institutes enables the youth to acquire excellent customer service skills, teamwork values, attention to detail and personal grooming abilities. This enables tourists to be contented with the quality of their travel and ensures good memories to be associated with the destination. Tourists satisfied with the quality of customer service are also more open to diving deeper into local culture and heritage and are welcoming to trying local culinary options instead of regular fast food options.

\section{Additional Government Support}

Apart from investing in provision of basic services, government also identifies tourism products, preserves heritage, environment and ecology. These activities of the government provide a much-needed additional support for development of slow food 
tourism as well. Government also launched campaigns to publicize the distinctive features of these new tourist destinations, including the authentic local Garhwali and Kumaoni culture. Tourists that arrive to these less- trafficked areas will find a more immersive experience in enjoying regional culinary delights. The government has also introduced regulations to ensure social, cultural \& environmental sustainability in Uttarakhand. Government- designated special tourism zones are investment havens for new business ventures in the state, providing ease of business for entrepreneurs interested in development of slow food tourism. Several entities involved in the promotion of slow food tourism are entitled to ask for fiscal and other incentives under the Mega Industrial Policy 2015, and MSME Policy, 2015. The government thus offers a wide range of benefits in terms of interest incentives, financial assistance, subsidies and concessions.

\section{CONCLUSION}

Slow food tourism is an engaging avenue in the modern era; it can show significant contribution to overall tourism development of a destination. In this paper it has been shown that Uttarakhand has several unique features that ideally indicate its vast scope for a successful slow food tourist destination. The study includes identification of potential sites for developing slow food tourism, and an examination of the overall scenario in the sector. The state offers a wide variety of heritage-rich style of cuisine such as Thenchwani, Phaan, Chaunsu and more to be a commercially viable destination for slow food tourism. In a survey among stakeholders from the tourism sector of Uttarakhand, observations regarding slow food tourism have been gathered from the perspectives of tourists, hoteliers, restaurateurs, tour guides and agents, and the local population. The results suggest that there is mutual agreement among these stakeholders about Uttarakhand's unexplored capacity to attract slow food tourists.

Next, five key factors have been identified as key in driving the growth of slow food tourism are namely, improved infrastructure, marketing and promotion activities, inter-industry cooperation, local population awareness, and government aid and support. The recent developments and action plans by Government of India and state government of Uttarakhand have encouraged and aided the development of slow food tourism in the state through contribution to different sectors like infrastructure development, marketing, quality control and service training.

\section{Practical Implications}

The present study provides interesting insights into the role of slow food in development of the tourism industry based in Uttarakhand. The study has offered insight into the development of slow food tourism as a supplement to regular tourism avenues. The subjective and open-ended research methodology for all stakeholders allows for a more nuanced understanding of the current scenario in slow food tourism. The factors derived in this study by accommodating primary data collected from tourists, hoteliers, restauranteurs, tourism service providers and the general local populace, show vast opportunities for growth. The knowledge of these factors can prove to be useful for both private entrepreneurs and government agencies in utilizing slow food tourism to boost local economy. The study includes a discussion on the developments in Uttarakhand tourism which have benefitted the expanse of slow food, and this could be helpful in drafting further administrative policies and schemes for the state tourism.

\section{Limitations and Future Research}

The present research uses the unstructured interview method to collect qualitative and subjective opinions of the respondents as primary data for its findings. More probing methodologies, such as means-end relationships or larger samples involving survey research could further strengthen insights. This study was conducted with respondents 
from a single state in India only, i.e. Uttarakhand. A pan-India analysis could be undertaken as basis for wider research. Comparisons with similar geographical locations across the globe could be taken into account in future research.

\section{REFERENCES}

Amuquandoh, F.E. (2011). International tourists' concerns about traditional foods in Ghana. in: Journal of Hospitality and Tourism Management, 18, 1, 1-9.

Atton, C. (2003), Reshaping social movement media for a new millennium. Social Movement Studies, 2, No.1, 3-15.

Baltescu, C.A. (2016). Culinary experiences as a key tourism attraction. Case Study: Brasov County. Bulletin of the Transilvania University of Brasov Economic Sciences. V, 9, 2, 107- 118.

Banerjee, O., Cicowiez, M., \& Gachot, S. (2015). A quantitative framework for assessing public investment in tourism-An application to Haiti. Tourism Management, 51, 1, 157-173.

Everett, S., \& Aitchison, C. (2008). The role of food tourism in sustaining regional identity: A case study of Cornwall, South West England. Journal of sustainable tourism, 16, 2, 150-167.

Hashimoto, A., \& Telfer, D.J. (2006). Selling Canadian culinary tourism: Branding the global and the regional product. Tourism Geographies, 8, 1, 31-55.

Jiménez Beltrán, J., López-Guzmán, T., \& Santa-Cruz, F.G. (2016). Gastronomy and tourism: Profile and motivation of international tourism in the city of Córdoba, Spain. Journal of Culinary Science \& Technology, 14, 4, 347-362.

Jung, T., Ineson, E.M., Kim, M., \& Yap, M.H. (2015). Influence of festival attribute qualities on Slow Food tourists' experience, satisfaction level and revisit intention: The case of the Mold Food and Drink Festival. Journal of Vacation Marketing, 21, 3, 277-288.

Karim, A., Shahrim, M., Chua, B.L., \& Salleh, H. (2009). Malaysia as a culinary tourism destination: international tourists' perspective. Journal of Tourism, Hospitality \& Culinary Arts, 1, 3, 1-16.

Kim, Y.G., Eves, A., \& Scarles, C. (2009). Building a model of local food consumption on trips and holidays: A grounded theory approach. International journal of hospitality management, 28, 3, 423-431.

Kivela, J., \& Crotts, J.C., (2005), Gastronomy tourism: A meaningful travel market segment. Journal of Culinary Science \& Technology, 4, 2, 39-51.

McKercher, B., Okumus, F., \& Okumus, B. (2008). Food tourism as a viable market segment: It's all how you cook the numbers. Journal of Travel \& Tourism Marketing, 25, 2, 137-148.

Miele, M., \& Murdoch, J. (2002). The practical aesthetics of traditional cuisines: slow food in Tuscany. Sociologiaruralis, 42, 4, 312-328.

Quan, S., \& Wang, N. (2004). Towards a structural model of the tourist experience: An illustration from food experiences in tourism. Tourism management, 25, 3, 297-305.

Rand, G.E.D., Heath, E., \& Alberts, N. (2003). The role of local and regional food in destination marketing: A South African situation analysis. Journal of Travel \& Tourism Marketing, 14, 3, 97-112.

Santich, B. (2004). The study of gastronomy and its relevance to hospitality education and training. International journal of hospitality management, 23, 1, 15-24.

Sidali, K.L., Kastenholz, E., \& Bianchi, R. (2015). Food tourism, niche markets and products in rural tourism: Combining the intimacy model and the experience economy as a rural development strategy. Journal of Sustainable Tourism, 23, 8, 1179-1197.

Upadhyay, Y., \& Sharma, D. (2014). Culinary preferences of foreign tourists in India. Journal of Vacation Marketing, 20, 1, 29-39.

Submitted:

12.04.2019
Revised:

06.09.2019
Accepted and published online 09.09.2019 